\title{
Being proactive about media engagement in first aid education
}

Emily Oliver \& Gareth Bentley

Digital media holds promise for first aid education, with opportunities to reach new learners and to deepen the engagement of existing learners. Understanding the fluctuation of usage of an app according to external events can help organizations and individuals to plan for follow up communications.

\section{Objective}

The British Red Cross (BRC) utilized data from Google Analytics ${ }^{\mathrm{TM}}$ for its first aid phone app to obtain insight into associations between session engagement and external events. The app was launched in 2010 and available on both iOS (apple) and Android mobile phones and tablet devices.

\section{Methods}

As part of our regular monitoring of the use of the app, we identified external events which occurred that either have an indirect or direct first aid aspect. Such events might be fictional (such as a first aid intervention on a character in a popular television drama) or real (such as a terror attack). We retrospectively consulted Google Analytics data to identify if these events produced any change from the regular pattern of sessions on days when there was no such event.

\section{Results}

During the period from January 2017- January 2018 the average daily session number was 1254 . The data revealed increased session numbers for the launch of a first aid product by another organization (2288 sessions on 4 January 2017) and trailers for and broadcast following a popular TV drama where a lead character suffered a heart attack (1487 sessions on 5 January 2017) (Figure 1). A video clip can be seen here:

https://youtu.be/pOIpLG7kwLs

For news events, such as a terror attack, increases occurred during national news broadcasts of these events (Figure 2) where sessions increased to 1480 on 22 March 2017 (a video clip of the news broadcast can be seen here: https://youtu.be/Ie4De25LFuU), and to 1642 on the following day (Figure 3). A video clip of the Prime Minister speaking about the event in the House of Commons can be seen here: 
Figure 1: App sessions recorded by Google Analytics on the day a TV drama was broadcast at 7pm

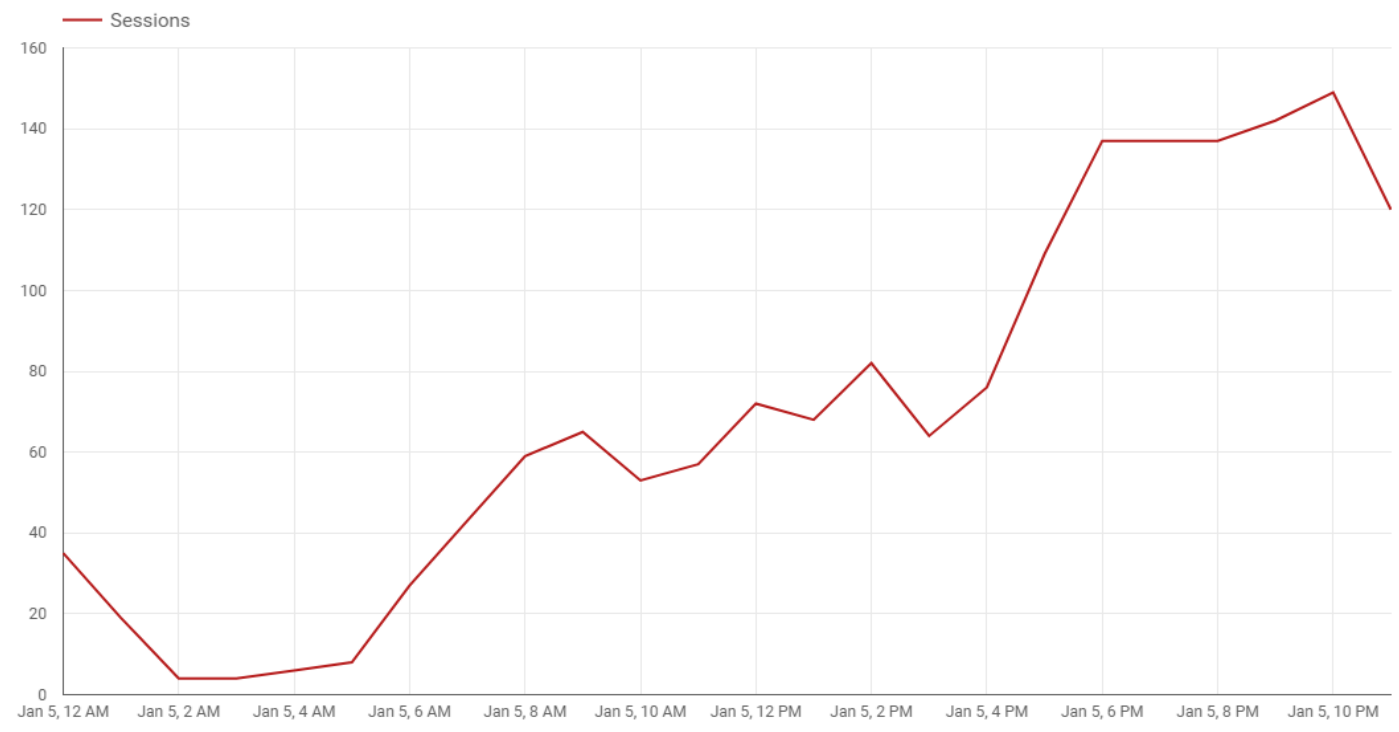

Figure 2: App sessions recorded by Google Analytics on the day of the Westminster attack (22 March 2017). News of the attack first began to emerge at around 3pm on the 22nd, however, it was not until around $5 \mathrm{pm}$ that a clear image of what had happened began to emerge. A corresponding increase in app sessions begins to emerge around $6 \mathrm{pm}$, coinciding with a prime-time news broadcast, peaking at 137 sessions at $8 \mathrm{pm}$, before rapidly declining to a more normal level.

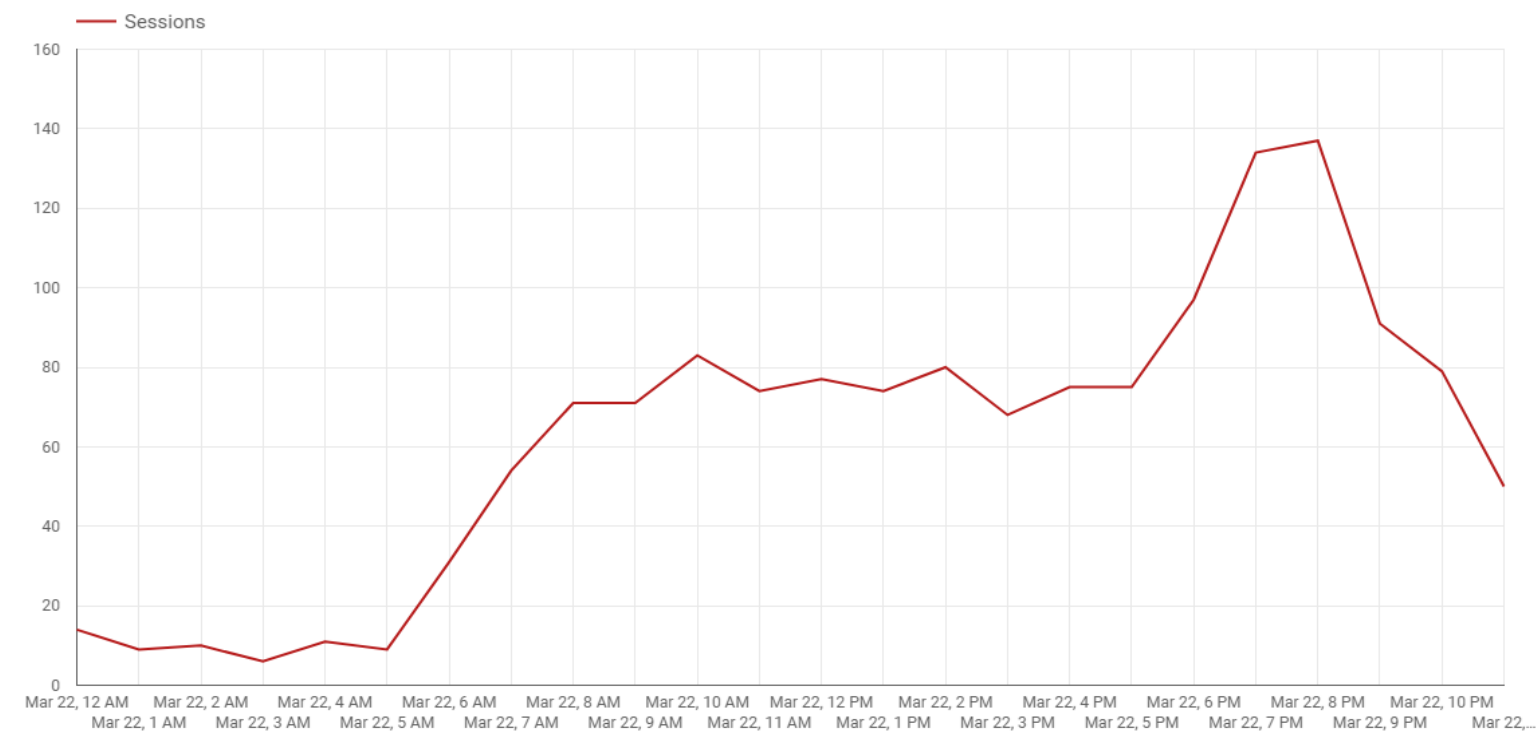


Figure 3: App sessions recorded by Google Analytics on the day after the Westminster attack. There is a spike to 142 sessions at around $11 \mathrm{am}$. This appears to coincide with several new developments on the story including, identification of the first casualty of the attack and a statement by the prime minister in the House of Commons.

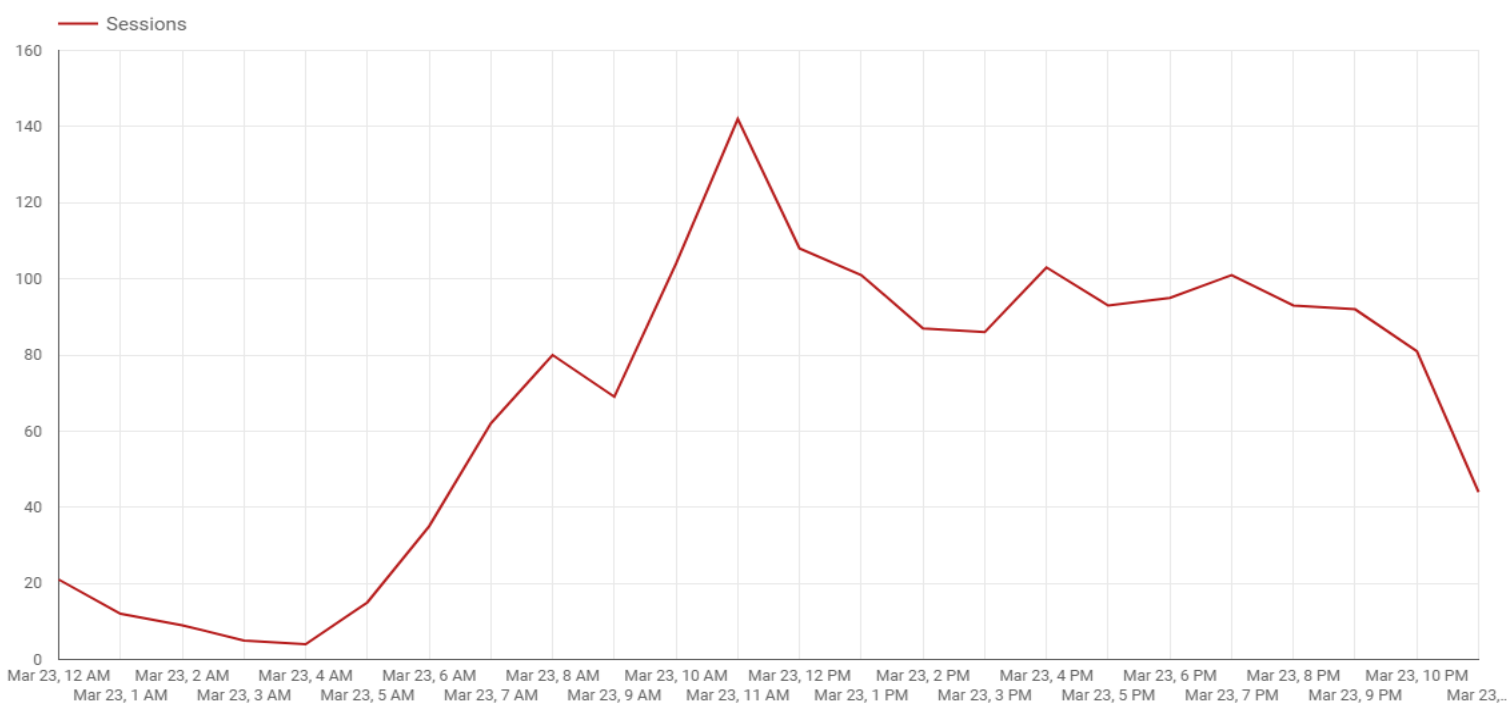

A further significant peak we saw over the period was during a national television breakfast show when a British Red Cross staff member was interviewed and mentioned the first aid app resulting in daily sessions rising to 2131. Figure 4 shows how this peak is depicted using data for the year until April 2018.

Figure 4: App sessions recorded by Google Analytics between January and April 2018. A BRC staff member appeared on breakfast TV and promoted the app on 26 January.

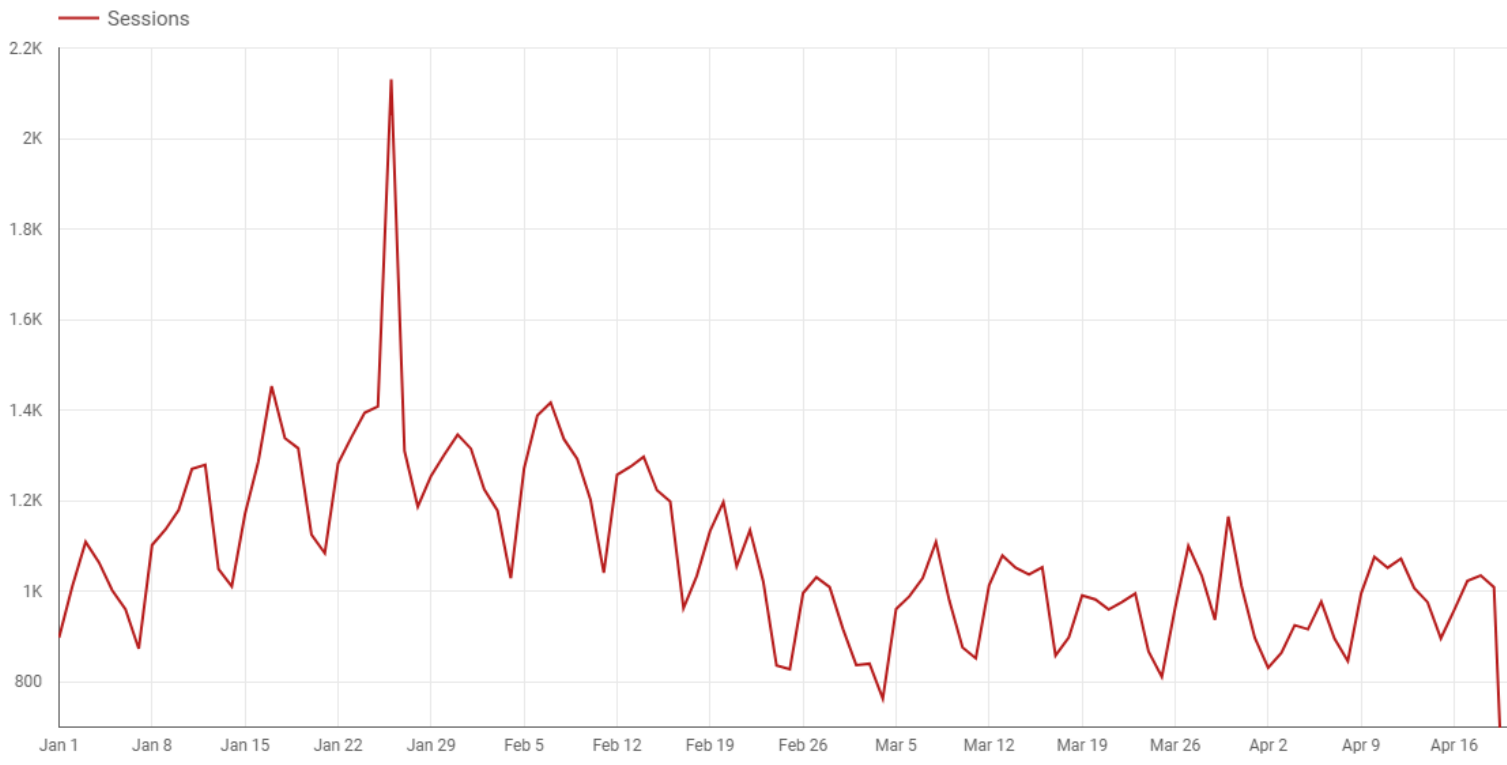


Conference Abstract

International First Aid Education Conference, 22-25 April 2018

\section{Conclusion}

Bearing in mind that the data has not been tested with specific "cause and effect" rigor, we can, nonetheless, conclude that engagement with the BRC first aid phone app in relation to external media events seems to be:

$>$ Inconsistent - some relevant events have more of an effect than others.

$>$ Temporary - as soon as the event ends, engagement returns to a normal level

$>$ Dependent on direct links to first aid - the more obvious the link, the greater the impact.

\section{Implications}

Access to analytical data showing use of digital tools can inform developers and communicators about how the public has understood an event in relation to a particular issue. This insight can inform planning the type and timing of response to relevant external events.

\section{Engagement with this topic at the International First Aid Education Conference, Canada, 2018}

Seminar participants were asked to consider a range of different events which might have had first aid implications. They discussed how they as individuals or their organizations might respond to such events and the sensitivities and implications of responding. They also considered the timing of their response. This activity highlighted the necessary care and introspection that might be required before responding. Responses might be to provide comfort or solidarity to victims, give first aid information or signpost to a course, or be a call for funds. Geographical proximity, direct relevance to the individual or organization, and political implications were all considered important in providing an appropriate media response.

\section{References}

Howe, A., Owen-Smith, V., \& Richardson, J. (2002). The impact of a television soap opera on the NHS Cervical Screening Programme in the North West of England. Journal of Public Health, 24(4), 299-304.

Kirkorian, H. L., \& Anderson, D. R. (2008). Learning from educational media. The handbook of children, media, and development, 188-213.

Sabido, M. (2004). The Origins of Entertainment-Education. In Singhal, A.; Cody, MJ; Rogers, E.;. and Sabido, M. Entertainment-Education and Social Change. History, Research, and Practice.

Vaughan, P. W., \& Rogers, E. M. (2000). A staged model of communication effects: Evidence from an entertainment-education radio soap opera in Tanzania. Journal of health communication, 5(3), 203-227 